\title{
Empowering Skepticism: Neuroethics Engagement with Tibetan Buddhist Monastics
}

\author{
Laura Specker Sullivan* \\ Fordham University, New York, NY, United States
}

Neuroethics has been incorporated into neuroscience training through the Science for Monks program since 2016. In this article, I describe this in-progress effort and I consider how the program has changed since this first year to develop into a pilot program in community-engaged participatory research with the monastic community. The current goals of the project are to train the monastics in social science research skills as a means of empowering them to harness their deep knowledge of ethics and to bring it to bear on ethical challenges in neuroscience, neurology, and neurotechnology.

Keywords: community-based participatory, cross-cultural, Neuroethics, Buddhism, engagement

OPEN ACCESS

Edited by:

Gillian Hue,

Emory University, United States

Reviewed by: Timothy Emmanuel Brown,

University of Washington,

United States

Paul Root Wolpe,

Emory University, United States

*Correspondence:

Laura Specker Sullivan

Ispeckersullivan@fordham.edu

Specialty section:

This article was submitted to

Science and Environmental

Communication,

a section of the journal

Frontiers in Communication

Received: 15 September 2021

Accepted: 18 November 2021

Published: 07 December 2021

Citation:

Specker Sullivan L (2021) Empowering Skepticism: Neuroethics Engagement with Tibetan Buddhist Monastics.

Front. Commun. 6:777803.

doi: 10.3389/fcomm.2021.777803

\section{INTRODUCTION}

When I was first approached about incorporating neuroethics into neuroscience training forTibetan Buddhist monastics through the Science for Monks program, I was reticent. These are monastics after all. Shouldn't they be teaching me about ethics? In one version of the narrative of my work with the monastics (Specker Sullivan 2020), my hesitance was unnecessary, and I discovered that I did have something to teach the monastics, after all. In that version of the narrative, I am the protagonist, uncovering some hidden truths about myself and my research agenda through this unique crosscultural encounter. But (perhaps thankfully) this is not that narrative. In hindsight, I could have been more reticent. Effective neuroethics engagement with the monastics requires repositioning my interests relative to their own and working to empower the monastic community to bring their existing knowledge to bear on neuroethics and to investigate the ethical issues in the brain sciences that are salient for them.

\section{NEUROETHICS AND SCIENCE FOR MONKS}

I was first invited to participate in the Science for Monks program in 2016, while a postdoctoral neuroethics fellow at the Center for Neurotechnology (CNT) at the University of Washington. ${ }^{1}$ Eric Chudler, a neuroscientist and the center's Executive Director, had taught neuroscience through the Science for Monks program for several years. I was brought on board to pilot neuroethics lessons alongside his neuroscience lessons, while also conducting preliminary neuroethics research of my own. From the beginning, my position was an intermediate one between teaching and research, on

${ }^{1}$ Science for Monks, like the Emory-Tibet Science Initiative, partners with Tibetan Buddhist monastic communities in India for scientific and leadership training and research. The two organizations have similar aims and sometimes work in the same communities, but they are different organizations with unique leadership structures and funding schemes. 
the model of cross-cultural exchange. I would share my own knowledge of contemporary neuroethics through a series of lessons; the monastics, in turn, would share their own perspectives on the intersection of ethics and the brain sciences through participatory exercises, surveys, and open discussion.

My background made me a good fit for this experiment. I had taught in Japan with the JET Programme and had studied crosscultural philosophy for my Ph.D., including 2 years spent as a researcher in Kyoto, Japan at the Kokoro Research Institute. I had some theoretical and practical experience with Buddhism through Japanese Zen Buddhism, but I had not worked directly with Tibetan Buddhist monastics. Through the CNT, I had developed an "Introduction to Neuroethics" slide set that I had used when teaching public and student groups, and I had collaborated with a primary school teacher to develop neuroethics modules for her class, but I had never paired neuroethics directly with neuroscience, and certainly not in a cross-cultural context. Nevertheless, I had experience being embedded in unfamiliar environments with the goal of intellectual exchange (not only in Japan, but as the sole philosopher in a neural engineering lab) and I hoped to draw on this skill set to create a meaningful relationship between myself and the monastics.

That first trip was, as one would expect, a learning experience-I suspect for me more than for the monastics. I had planned to begin my lecture the way I usually do in the United States, by asking the students to define "ethics." It turns out that this pedagogical technique relies on a cultural cohesiveness that did not exist between me and the monastics. Not only do I not know Tibetan, but I had not anticipated the multiple translations of this term. Faced with the prospect that the word "ethics" had different meanings for monastics than for lay people, for teachers than for students, I soon walked back this broad, top-down approach. Better to begin with the particular ethical issues that arose within neuroscience and neurology, I reasoned, since these are not abstract concepts but concrete problems, thick with context.

This approach turned out to be more successful. I introduced the monastics to the "rubber hand illusion," where someone can be made to experience sensation in a rubber hand unattached to their body. I used the illusion as an entry to a discussion of how physical sensations in one's body can lead to the sense of body ownership, and how this might raise questions about the significance of neural prostheses that are fully integrated into one's body schema. They learned about cutting edge techniques in neurostimulation, and the types of feelings and thoughts that such stimulation can occasion. We argued, in my impromptu office hours, over whether brain stimulation could make someone "too happy" or could change their sense of self.

After the snafu over ethics language on the first day, the rest of the sessions went more smoothly. At the end of the 2-week joint neuroscience-neuroethics session, I administered a survey I had developed on-site from my background in neuroethics, my conversations with the monastics, and informal worksheets I had distributed during the neuroethics sessions, asking them a set of Likert scale questions about how they thought about various neuroethical issues. I worked with my Tibetan translator to create a consent procedure that would fit my review board's requirements, while also being intelligible to the norms of the monastic community, and this had been initiated at the beginning of the session.

Some results piqued my interest, namely the monastics' skepticism about neuroscience as a route to human well-being and achievement. Science, in their estimation, was a fast-moving train that, once on track, was hard to slow, even if misgivings about the direction had developed. I didn't think they were wrong, but I wanted to know more.

In 2017 I returned to India to conduct one-on-one interviews with senior monastics alongside offering neuroethics lessons to existing science classes in the monastic community, building from the groundwork of this first visit and the survey results. This time, I resolved to be more interactive, and to focus on the monastics' knowledge, rather than my own. I aimed to ask broad, open-ended questions to better understand how the monastics were thinking about the intersection of neuroscience and ethics. I would not ask them to define ethics, I resolved, but would phrase my questions as requests for advice from fictional characters in tricky situations that involved neuroscience, neurology, and neurotechnology. This was a way of engaging with ethical questions that was more familiar to the monastics. While the science was important, the central concern was the human predicament the characters faced. The work ethicists do with scientists and clinicians in North America and Europe isn't so different, after all.

The results were intriguing, although not entirely surprising (Specker Sullivan 2021). The senior monastics continued to express skepticism about the use of science and technology to improve human lives. In clear-cut cases, new medical developments played a salutary role; everyone could see that brain injuries, like a broken limb, were a problem that needed mending. But when it came to using medical technology for basic mental health, or even to boost mental performance, they were deeply skeptical. The structure of the questions, describing situations where people were ill, or near-death, and a decision needed to be made, privileged the kinds of situations that I saw as problematic. The questions I asked relied on unstated premises: when I offered the monastics a dilemma and asked them which of two branching paths to a solution they would take, they wondered why such a dilemma arose in the first place.

So, in 2019 I pivoted the neuroethics project once again, to pilot a project in which I hoped the perspective from my own position as an American neuroethicist would fade even further into the background. I would live at a nunnery and work with the nuns to develop a more participatory approach to neuroethics engagement. One motivation for this pivot was my hesitancy about the methods I had been using to engage the monastics in connecting ethics with neuroscience, which were drawn from the ethnographic theory I learned through my graduate work in Japanese Studies. Traditional ethnography, despite shifting to describe objects of study as "participants," does not really operate on equal partnership with the communities it studies. The locus of power remains with the researcher, who in designing the questions and the structure of the study decides what is important, and what is tangential, to the area being studied. 
While my training in neuroethics grounds my expertise in this type of research, this is just to say that I have worked within a particular tradition of scholarship that is concerned with the intersection of science and questions about what we, as human beings, should do. If I wanted to get outside that perspective to appreciate what mattered to the monastics, I would have to rethink my methods.

\section{PURPOSES AND METHODS OF NEUROETHICS ENGAGEMENT WITH MONASTICS}

Rethinking my methods of engagement with the monastics meant reflecting on the fundamental aims of the project. Why, as a neuroethicist, was I working with the monastics in the first place?

What I realized early on was that engaging with the monastic community through neuroethics revealed a pathway to neuroscience training due to the affinities between the aims of neuroethics as a field and the ethical orientation of Tibetan Buddhism. While others have pointed out the connections between the scientific study of the mind and the monastics' rigorous attention to first-person mental experience in their meditation practices (Varela et al., 1991), a more fundamental link is the shared purpose behind both of our practices.

Without precluding science for its own sake, neuroethics asks scientists, technologists, and clinicians to consider the end goal for which their practices are used, and to consider what benefits and harms might result, what their own motivations are, and whether any individuals might be wronged in the process. Likewise, Buddhist practices aim at benefitting sentient beings, developing altruistic motivations, and avoiding fundamental ethical wrongs. In this way, neuroethics can provide a missing link between Buddhist practice and scientific practice, by facilitating reflection on why it is meaningful to seek to understand the world through these scientific and religious traditions alike.

Due to the intellectual connections between neuroethics and Tibetan Buddhism, programs such as Science for Monks and the Emory-Tibet Science Initiative open a door to engaging with the monastics as partners in research and education, beyond relationships as teachers and students. While both programs ostensibly are oriented around scientific training for the monastic community, they are better understood as programs of cross-cultural intellectual exchange. Indeed, numerous interdisciplinary research programs have grown out of each program, with the broad goal of mutual benefit. ${ }^{2}$ The scientific community and the monastic community are both trying to

\footnotetext{
${ }^{2}$ This is clear in the mission statements of the two organizations. Science for monks: "The mission of Science for Monks is to nurture leaders who are establishing the indigenous capacity of the Tibetan monastic community to engage in new science learning and dialogue" (http://www.scienceformonksandnuns.org/about/). ETSI: "The Emory-Tibet Science Initiative is committed to bringing together the best of the Western and Tibetan Buddhist intellectual traditions for the creation, development and dissemination of knowledge and practices that will benefit humanity" (https://tibet.emory.edu/mission.html).
}

improve the human condition, and each specialty offers one particular method of doing just that. Upon reflecting on this shared purpose, I began to consider how to engage the monastic community more fully as partners in exploring the connections between Buddhism and neuroscience through neuroethics.

One method for developing a partnership with the monastics is community-based participatory research, or CBPR. In part due to developments in qualitative research that have occurred within public health, CBPR has been advocated as a more equitable model of cross-cultural research (Israel et al., 2010). The goal of CBPR is to implement just and equitable research practices across culture and other barriers, such as race and class, that balance the relative privilege of the researcher with the empowerment of the local community to identify and to achieve their own goals. While CBPR has typically been employed in addressing health disparities, it has promise for research that aims at equitably investigating ethical issues with scientific and medical developments across cultures.

CBPR is sometimes defined not as a particular set of methods, but in terms of the attitudes of researchers who prioritize democratizing knowledge and deconstructing power such that the experiential knowledge of communities is prioritized, empowering those communities (Minkler 2004). Yet balancing power between researchers and communities can be exceedingly difficult (Postma 2008). Differences in institutional structure, communication style, decision-making authority, and so on can create barriers to equitable participation. So, while an attitude of collaboration and mutual empowerment is helpful, it only goes so far. Structures that allow for new methods of intellectual engagement are needed to encourage participation.

These procedural challenges with CBPR can lead to ethical challenges (Minkler 2004; Mikesell et al., 2013; Wilson et al., 2019). A key factor in successful CBPR is building trust with local communities such that members believe their community will be strengthened by collaboration, not taken advantage of (Blacksher et al., 2016). Yet that trust must be warranted, and not gained superficially. In other words, community trust is earned when researchers are trustworthy. Researchers must also understand their own institutional limitations, and not overpromise the terms of their engagement and the benefits they can provide. The central ethical concern with CBPR is the tension between insiders and outsiders (Mikesell et al., 2013). These tensions can come from a variety of sources, such as different values, expectations, assumptions, priorities, and beliefs. While communication and transparency around differences can mitigate the tension they might cause, these differences do not disappear.

Despite these challenges, community-based participatory methods have much to offer neuroethics engagement with Buddhist monastic communities who are participating in science education. As the monastics develop scientific fluency, they become better positioned to identify their values and priorities with respect to scientific practices and developments. Further, they gain the language with which to express concern and skepticism, as well as excitement and optimism, about the potential for scientific advancements to change significant dimensions of human life. Using CBPR methods for 
neuroethics engagement is one way to empower the monastic community to make their ideas on the benefits and risks of scientific practices known and to potentially impact those practices.

My own community-based work with the nuns is still in the very early stages. In 2019, I spent 2 weeks at the nunnery, leading classes on ethical issues in science that were part science education, part social science methods training. The goal is to empower the nuns, through social science methods, to collect their community's perspectives on ethics in science, so that any resulting neuroethics scholarship is not driven by my own agenda or interests, but by theirs. In this research program, I aim to be an advisor on methods and processes but not on content.

It is due to the complexity of community-engaged work that I believe I could have been more reticent about my work with the monastic community at the outset. I was, admittedly, naïve in my certainty that with a short introduction, the monastics and I would be able to share an appreciation of ethical issues in the brain sciences. There are unstated premises about what science is and why it matters that need to be acknowledged before we can even imagine a discussion of what we ought to do with it. Nevertheless, while this program is still in its early stages, I am optimistic that, if completed, it would empower the monastic community to influence the global discourse on the ethical dimensions of scientific advancements. This is not to say that the monastics need engagement with neuroethics to facilitate their own empowerment. Their experience and knowledge is powerful, and it could impact neuroethics-if we can learn to acknowledge what is already there.

\section{CONCLUSION: BENEFITS OF PARTICIPATORY ENGAGEMENT}

Neuroethics engagement with the monastic community can link scientific study with Tibetan Buddhism's ethical aims; it can also spark consideration of the reasons why scientific engagement matters for the monastics. Just as with scientists, monastics are curious about the world and their own experience, they value truth and accurate explanations, and they would like to see the conditions for all inhabitants of the world improve. As scientists partner with monastics, they may begin to question why scientific practice is a valuable tool for the monastics, who already have centuries-old practices developed for similar purposes (e.g., in the field of medicine, mental and physical health). The monastics themselves can encourage this questioning, asking why certain scientific experiments are carried out or technologies pursued if they do not offer means to sustainable well-being. Treating the

\section{REFERENCES}

Blacksher, E., Nelson, C., Van Dyke, E., Echo-Hawk, A., Bassett, D., Buchwald, D., et al. (2016). Conversations about Community-Based Participatory Research and Trust: "We Are Explorers Together". Prog. Comm. Health Part. 10 (2), 305-309. doi:10.1353/cpr.2016.0039 monastics as true partners in intellectual inquiry requires taking these questions to heart.

Yet taking up monastics' questions does not in itself distinguish an intellectual partnership. It is entirely possible to superficially entertain a set of questions while nevertheless focusing attention on questions that one considers more scientifically relevant. Developing an equitable partnership with the monastics requires science training that revolves around their interests and questions. As neuroethics engagement with the monastics develops, one challenge is to similarly structure neuroethics discussions around ethical issues the monastics care most about. This includes, for example, talking about animal sentience and whether it should alter the norms of scientific research. While many neuroethics programs avoid this issue due to its fraught political status, it is an issue that many monastics care deeply about and it deserves to be taken up more seriously.

One of the goals of neuroethics engagement in the Science for Monks program has been to build a skill set in social science research skills that empowers monastics to investigate neuroethical perspectives within their own community. The results of their study could have a profound effect on current neuroethics research programs. While much of neuroethics research embraces scientific and technological development, taking a "not if but when" approach, monastic-initiated research might ask us to reconsider the purposes for which scientific developments are pursued.

In the early years of scientific engagement with the monastics, programs necessarily proceeded through trial and error: seeing which projects worked and which failed and building scientific literacy among the monastics so as to work with them as partners. Neuroethics engagement represents the fruit of these efforts, allowing ethicists to work alongside monastics on issues of common concern. Now, the time is ripe to develop capabilities within the monastic community for collaborative neuroethics scholarship that emerges from their own interests.

\section{DATA AVAILABILITY STATEMENT}

The original contributions presented in the study are included in the article/supplementary material, further inquiries can be directed to the corresponding author.

\section{AUTHOR CONTRIBUTIONS}

The author confirms being the sole contributor of this work and has approved it for publication.

Israel, B. A. (2010). Community-Based Participatory Research: A CapacityBuildingApproach for Policy Advocacy Aimed at Eliminating Health Disparities. Am. J. Public Health 100 (11), 2094-2102. doi:10.2105/ AJPH.2009.170506

Mikesell, L., Bromley, E., and Khodyakov, D. (2013). Ethical CommunityEngaged Research: A Literature Review. Am. J. Public Health 103 (12), e7-e14. doi:10.2105/AJPH.2013.301605 
Minkler, M. (2004). Ethical Challenges for the 'outside' Researcher in Community Basedparticipatory Research. Health. Educ. Behav. 31 (6), 684-697. doi:10.1177/1090198104269566

Postma, J. (2008). Balancing Power Among Academic and Community Partners: The Case of El Proyecto Bienestar. J. Empirical Res. Hum. Res. Ethics Int. J. 3 (2), 17-32. doi:10.1525/jer.2008.3.2.17

Specker Sullivan, L. (2021). Mistaken Compassion: Tibetan Buddhist Perspectives on Neuroethics. Am. J. Bioeth. Neurosci. doi:10.1080/ 21507740.2021 .1939460

Specker Sullivan, L. (2020). Neuroethics with Tibetan Buddhist Monastics. Atlanta, GA: The Neuroethics Blog. Available at: http://www.theneuroethicsblog.com/ 2020/03/neuroethics-with-tibetan-buddhist.html.

Varela, F., Rosch, E., and Thompson, E. (1991). The Embodied Mind. MIT Press.

Wilson, E., Kenny, A., and Dickson-Swift, V. (2019). Ethical Challenges in Community-Based Participatory Research: A Scoping Review. Qual. Health Res. 28 (2), 189-199. doi:10.1177/1049732317690721
Conflict of Interest: The author declares that the research was conducted in the absence of any commercial or financial relationships that could be construed as a potential conflict of interest.

The handling editor declared a past collaboration with the author.

Publisher's Note: All claims expressed in this article are solely those of the authors and do not necessarily represent those of their affiliated organizations, or those of the publisher, the editors and the reviewers. Any product that may be evaluated in this article, or claim that may be made by its manufacturer, is not guaranteed or endorsed by the publisher.

Copyright $\odot 2021$ Specker Sullivan. This is an open-access article distributed under the terms of the Creative Commons Attribution License (CC BY). The use, distribution or reproduction in other forums is permitted, provided the original author(s) and the copyright owner(s) are credited and that the original publication in this journal is cited, in accordance with accepted academic practice. No use, distribution or reproduction is permitted which does not comply with these terms. 